\title{
A MARINE FUNGUS PLECTOSPIRA DUBIA N.SP. [SAPROLEGNIACEAE], INFECTING CRUSTACEAN EGGS AND SMALL CRUSTACEA
}

\author{
By D. Atkins, D.Sc.
}

(Text-figs. I-5)

Among eggs, cut from a recently dead Pinnotheres pisum on II June I953 (spawned on 9 May), about six were infected with a fungus Plectospira dubia n.sp. not previously observed and quite distinct from both Leptolegnia marina (Atkins, I929, I954a) and Pythium thalassium (Atkins, I954b) also parasitic in crustacean eggs. The parent showed no fungus in the gills (the body was not examined). The crab had been in Plymouth laboratory tank water of salinity of 36-37\% with added townettings from 26 August I952 to the time of death, for 3 months of the time within a Mytilus edulis. The eggs were kept in a finger bowl, as it was hoped they would hatch, but in little more than a week most of the eggs of the small egg-mass were infected. This occurred with temperatures between 14 and $15^{\circ} \mathrm{C}$.

The same fungus developed independently in the eggs taken, in clean and healthy condition, from a recently dead Gonoplax rhomboides which had been in the laboratory for some time. This infection started in the form of a mycelium given over entirely to the production of gemmae; but mycelia giving rise to sporangia developed in other eggs of this egg-mass within a few days (see also p. 728).

The following crustacean eggs became infected by placing one to several infected eggs with them: Typton spongicola, Crangon vulgaris, Leander serratus, Macropodia sp. and Portunus depurator. All infected eggs had embryos in various stages of development, up to about two-thirds developed.

The fungus is of dense, but slow, growth. The first sign of infection in the egg was the development of a space between the inner and outer egg membranes, and in this space the young infecting hyphae first appeared (Fig. ID). The space increased with the growth of the infection and this, together with some bulging of the sporangia beyond the egg, increased the size of infected eggs. The healthy egg of Pinnotheres pisum is about $0.33 \mathrm{~mm}$ in diameter, that of the infected egg about $0.5 \mathrm{~mm}$. The egg of Gonoplax rhomboides increased with infection from the normal diameter of about $0.5 \mathrm{~mm}$ to $0.65 \mathrm{~mm}$; that of Portunus depurator from about $0.32 \mathrm{~mm}$ to $0.42 \mathrm{~mm}$; and that of Crangon vulgaris from 0.8 by $0.58 \mathrm{~mm}$ to $\mathrm{I} \cdot 3$ by $0.8 \mathrm{~mm}$. The eggs of Gonoplax rhomboides with the gemmae stage of the fungus did not show increase in size. 
Plectospira dubia while an active parasite-infecting hyphae entering eggs containing embryos with heart beating-does not appear to be as severely pathogenic as Leptolegnia marina (Atkins, 1929, I954a). The hyphae seem to be first attracted toward the yolk remnant, but a few prezoeae and zoeae have become infected and also three Evadne: it is possible that the latter may have been moribund before infection.

The method of sprouting of the infecting spores has not been clearly seen, as they tend to collect in groups, which soon become coated with other organisms.

\section{Mycelial characteristics}

The hyphae are generally stout; the mycelium becomes irregularly branched; the ends of branches tend to be swollen. Young hyphae soon after entry attain a width of about $27 \mu$, and the main hyphae of a young mycelium may be $50 \mu$ (Fig. IC). The cytoplasm is hyaline, but with groups of minute shining granules, the groups more or less evenly spaced, as though collected round nuclei (Fig. IA, B, D).

\section{Asexual reproduction}

Within the host the growth soon becomes irregular (Fig. IA), the branches inflated and bulbous, up to about $100 \mu$ wide, acting as sporangia. So far as can be seen in such a restricted space there is no distinction between vegetative and reproductive hyphae, and eventually the whole of the mycelium is used up in spore-formation and the host is left a network of empty sporangia (Fig. 2A).

The inflated sporangia for the most part are within the host tissue, but characteristically bulge beyond the crustacean egg (Fig. 2B, C); occasionally much of a sporangium may be extra-matrical. In a covered dish from which there had been some slight evaporation with increased salinity the extramatrical portions of sporangia were exceptionally inflated (Fig. 2D). The inflated sporangia with large central vacuole and widely spaced spore initials gives to an infected egg a coarsely vesicular appearance.

Sporangia are provided with one or more efferent hyphae, 50-400 $\mu$ long, and $10-30 \mu$ wide (Fig. 3). When long the tubes are frequently corrugated and may be twisted (Fig. 3A). Sporangia quite often have paired efferent hyphae (Fig. 3D).

Spores are formed not only in the sporangia, but in the efferent hyphae, except for an apical portion of a length up to about $50 \mu$, which remains hyaline. During spore formation the tip of the efferent hypha frequently enlarges and becomes flattened across the top and when the tip dissolves or gives way-it is not known which occurs-the aperture is then left with flared lips. Other shapes of aperture are shown in Fig. 3C. Occasionally the pore may be exceedingly small, so that zoospores in the second motile stage, 


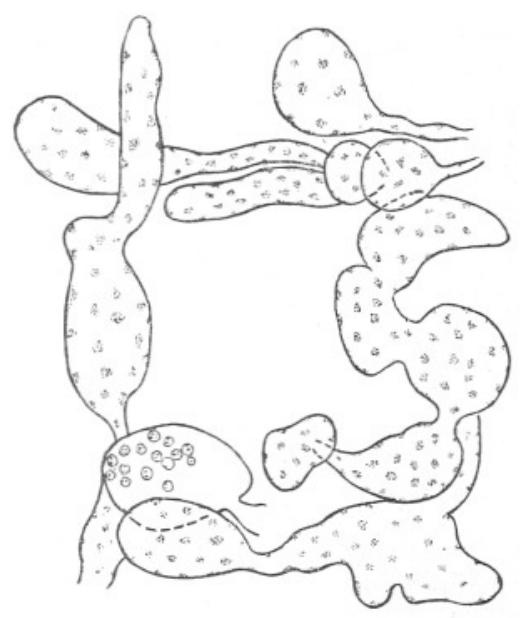

A

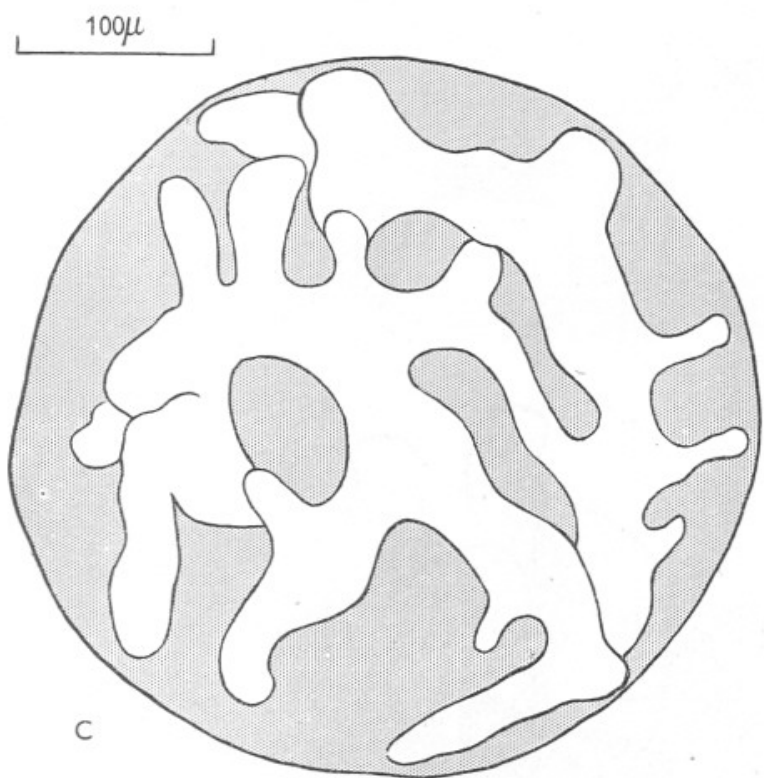

Fig. I. Plectospira dubia. A, mycelium dissected from egg of Macropodia; B, group of young infecting hyphae below dorsal cuticle of Evadne; c, young mycelium in egg of Pinnotheres pisum; D, young hypha growing in space between outer egg membrane and embryo. 

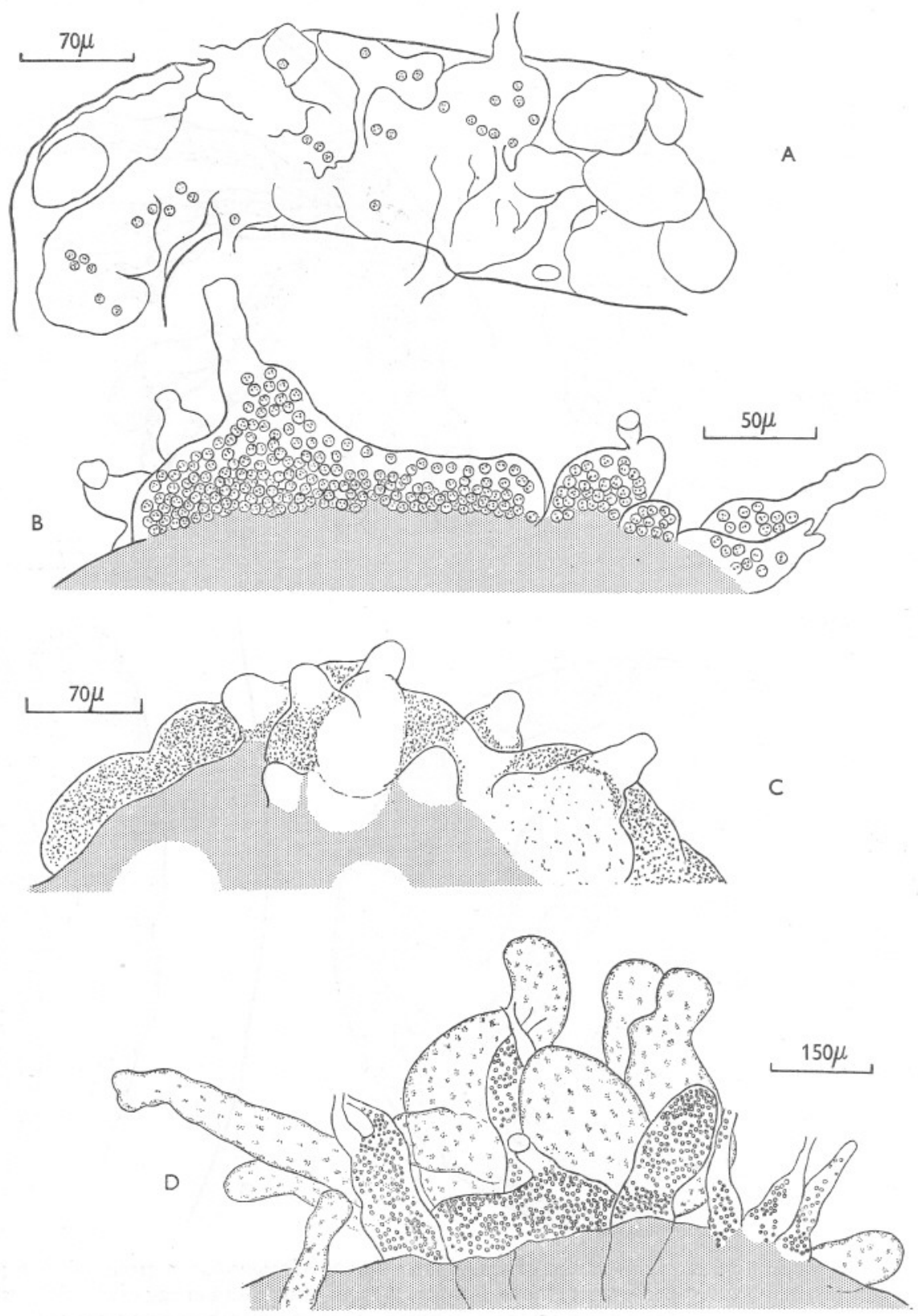

Fig. 2. Plectospira dubia. A, sporangia, empty except for a few encysted spores, within abdomen of a zoea; B, sporangia, containing encysted spores, projecting from egg of Pinnotheres pisum; c, young sporangia, with large vacuoles, projecting from egg of $P$. pisum: the growing efferent hyphae have clear tips; $\mathrm{D}$, much inflated sporangia projecting from egg of Crangon vulgaris: taken from a dish in which there had been some increase in salinity. 
in passing through are constricted and have a difficult and slow passage: one was observed to be pinched almost in two, the portion beyond the aperture rounding up as did the larger portion inside, so blocking the aperture. The tips of all the external hyphae of a sporangium do not always give way, as occurs also in Plectospira myriandra and P.gemmifera (Drechsler, I927, I929).

Pyriform flagellated zoospores are formed within the sporangium and efferent hyphae.
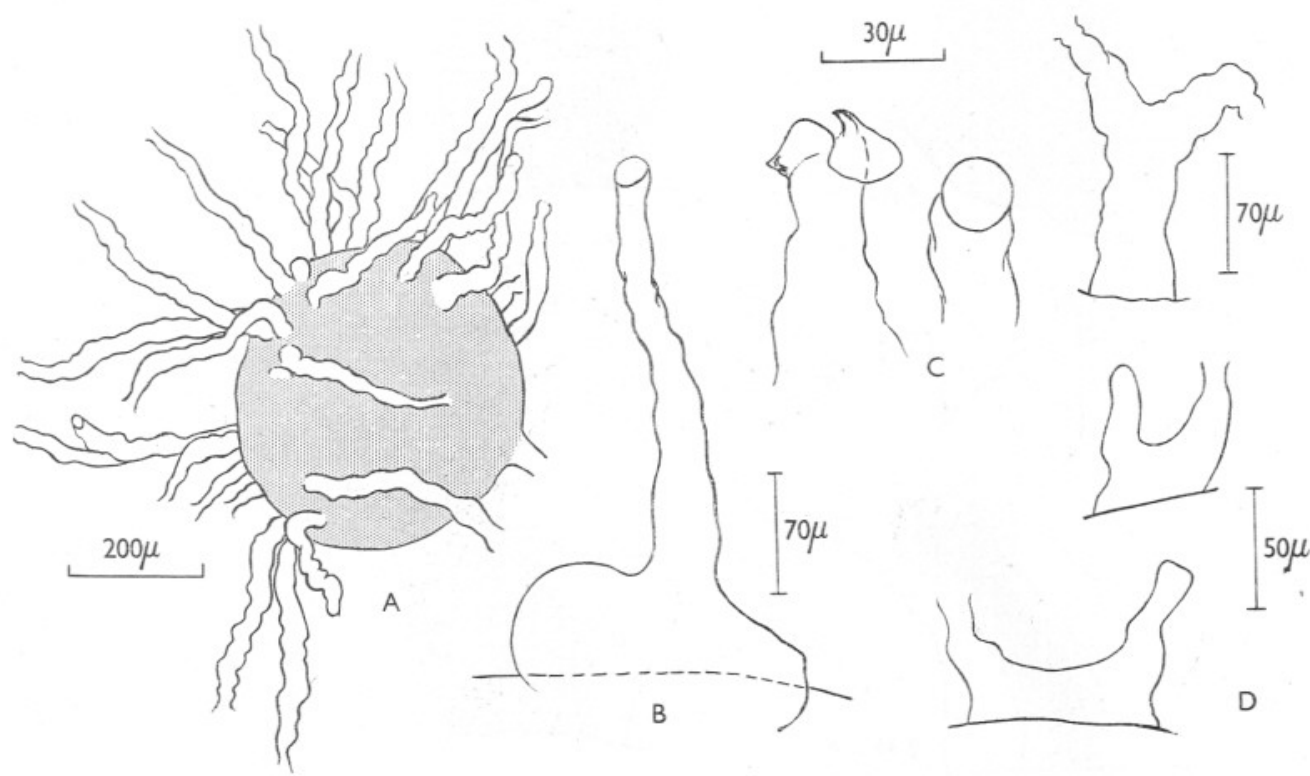

Fig. 3. Plectospira dubia. A, corrugated efferent hyphae on egg of Pinnotheres pisum; B, external portion of sporangium with a single efferent hypha; C, apertures of efferent hyphae. D, three external portions of sporangia with paired efferent hyphae, two of which have not functioned.

Only about nine instances of zoospore formation have been watched, for it occurs mostly at night, rarely during the day. Spore initials (Fig. 5c) are visible for some hours, for as many as five, before moving zoospores are formed. The active formation of zoospores is generally preceded by contraction of the contents of the sporangium. The degree of contraction varies, the contents rapidly withdrawing entirely from the efferent hyphae, and in extreme instances contracting from the wall of the sporangium. It would seem that contraction is greater if it occurs when the spore initials are not widely separated. In one sporangium, watched between 4 and 9.20 p.m. G.M.T. (Fig. 4), the sudden contraction was so great that the appearance of spore initials was lost, and the contents of the sporangium appeared darkly granular with a lighter edge. There followed a gradual expansion, small rounded 

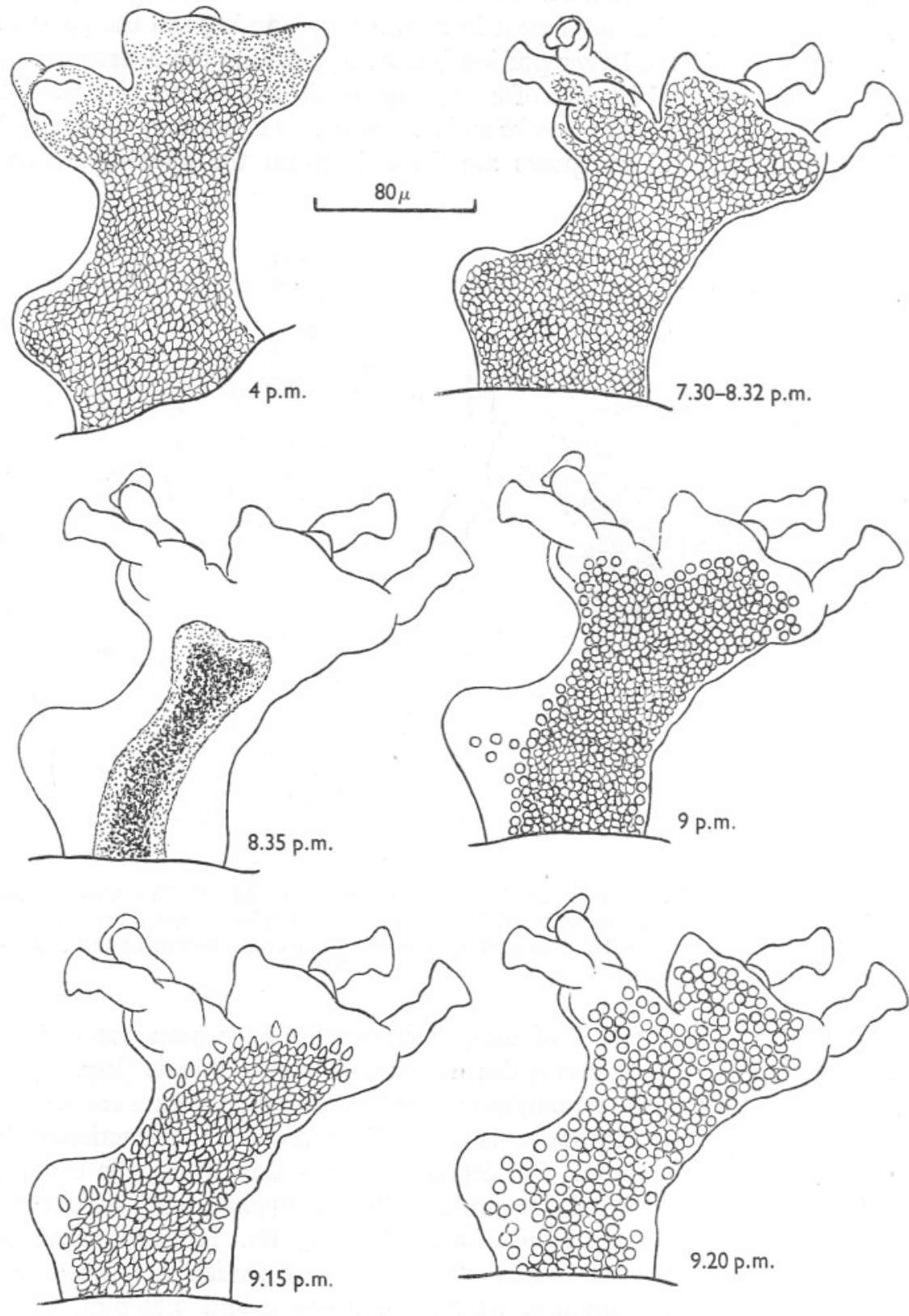

Fig. 4. Plectospira dubia. Formation of zoospores in external portion of a sporangium: for description see text pp. 725-7. 
bodies appearing on the edge of the protoplasmic mass. Expansion continued and rounded spores became clearly visible; these gradually became pear-shaped, and the appearance was then of a moving and heaving mass of spores, which were evidently flagellated. On the outskirts of the main body single zoospores rocked gently. A high-power objective was lowered into the water to get a clearer view, but unfortunately it had an adverse effect, for the spores rapidly rounded up within the sporangium.

In another sporangium kept under observation at the same time, in a separate watch-glass, the spore initials were widely spaced before contraction, and although the contents withdrew from the two efferent hyphae of a length of about $\mathrm{I} 50 \mu$, there was little contraction in the sporangium itself: the spore initials remained visible. On expansion, the spores reached about half-way along the efferent hyphae. Moving zoospores were visible, but although a few spores moved to near the end of the efferent hyphae, none escaped; all encysted.

One day, from about 5 p.m. G.M.T., four efferent hyphae were kept under observation. In three the process of spore formation was as described, with moderate degree of contraction and expansion of contents of the sporangium and all spores encysted; none escaped. In the fourth, on expansion, a single string of zoospores, diamond-shaped and attached end to end by delicate strands of protoplasm, passed up the efferent hypha. At intervals eight feebly rocking pyriform zoospores slowly emerged from the aperture, swam away slowly at first, then with more speed. No doubt these zoospores were biflagellate, as usual in many members of the Saprolegniacea, but it was not possible to determine this, as it had been found that lowering a high-power objective into the water caused encystment. The remaining spores encysted in the sporangium and did not begin to emerge from the efferent hypha in the second motile stage until about 8 p.m. G.M.T. next day.

It is apparently during the formation of the pyriform zoospores that the tips of the efferent hyphae give way, but it is not always possible to be sure that a pore is actually present unless zoospores escape.

The pyriform zoospores are only feebly active within the sporangium, and that usually for not more than 5-Io min, or less. The time they remain encysted varies: sporangia left with newly encysted spores overnight may be found with empty cysts the next morning, or spores may still be present 20 hours later.

The fact that many crustacean eggs contained mycelia crowded with encysted spores confirms that the behaviour of the pyriform zoospores is as observed in the few instances recorded.

Zoospores in the first motile stage are about ro $\mu$ long and when encysted are $7-8 \mu$ in diameter.

Owing to the large central vacuole of the sporangium, the generally wide spacing of the spore initials and the length of clear protoplasm at the end of 
the efferent hyphae, there is sufficient space for at least some of the pyriform zoospores to round up; these seem to collect round the walls, leaving a central space through which the more internally situated zoospores can pass on their way to the exterior. When crowded the encysted spores are angular.

Zoospores have not been seen actually emerging from cysts within the sporangium, but were seen escaping singly at intervals through the apertures of the efferent hyphae at all times of the day. They are rather long and thin, distinctly grooved longitudinally, with two long, laterally inserted, flagella, one directed anteriorly and one posteriorly: the flagella work with a looping motion. Zoospores in the second motile stage are II $-\mathrm{I} 2 \mu$ long: when encysted they are $6-7 \mu$ in diameter. Time normally spent in the second swimming stage is unknown. They have been seen to encyst within a few minutes of emerging from the sporangium, but this is unusual and probably due to unfavourable conditions on a slide. These zoospores swim actively within the sporangium and efferent hyphae seeking a way of escape, for the tips of all efferent hyphae do not give way; on emergence they swim rapidly away.

The walls of the sporangia and efferent hyphae are persistent and do not disintegrate or rupture irregularly as do the sporangia of Thaustotheca and some species of Dictyuchus for the liberation of the laterally biflagellate zoospores (Coker \& Matthews, 1937, pp. 50, 52).

The thin-walled empty cysts are visible in the sporangia and basal parts of efferent hyphae after the escape of the zoospores: they are round or angular according to the degree of crowding.

\section{Proliferation}

Very occasionally proliferation occurs, a new sporangium growing up within the old one (Fig. 5A, B), as occasionally in Leptolegnia and typically in Saprolegnia. The new growth may extend beyond the old (Fig. 5B), or may not reach the end of the old efferent hyphae, when it may send out short exit tubes; in the example figured there were eight (Fig. 5A).

\section{Gemmae}

The first appearance of Plectospira dubia in eggs (with embryos two-thirds developed) removed from a recently dead Gonoplax rhomboides occurred a week after their removal, and was under a form quite different from that previously seen: it was distinctive because of spherical bodies of varying size, showing white by reflected and dark by transmitted light. The plants under this form did not entirely fill the egg, and infected eggs were no larger than healthy ones, but the magenta colour from the small yolk remnant was diffused throughout the egg. Young plants dissected out from the egg had the appearance shown in Fig. 5D. The cytoplasm was finely and densely granular; the mycelium was producing rounded bodies up to about $100 \mu$ in diameter, 

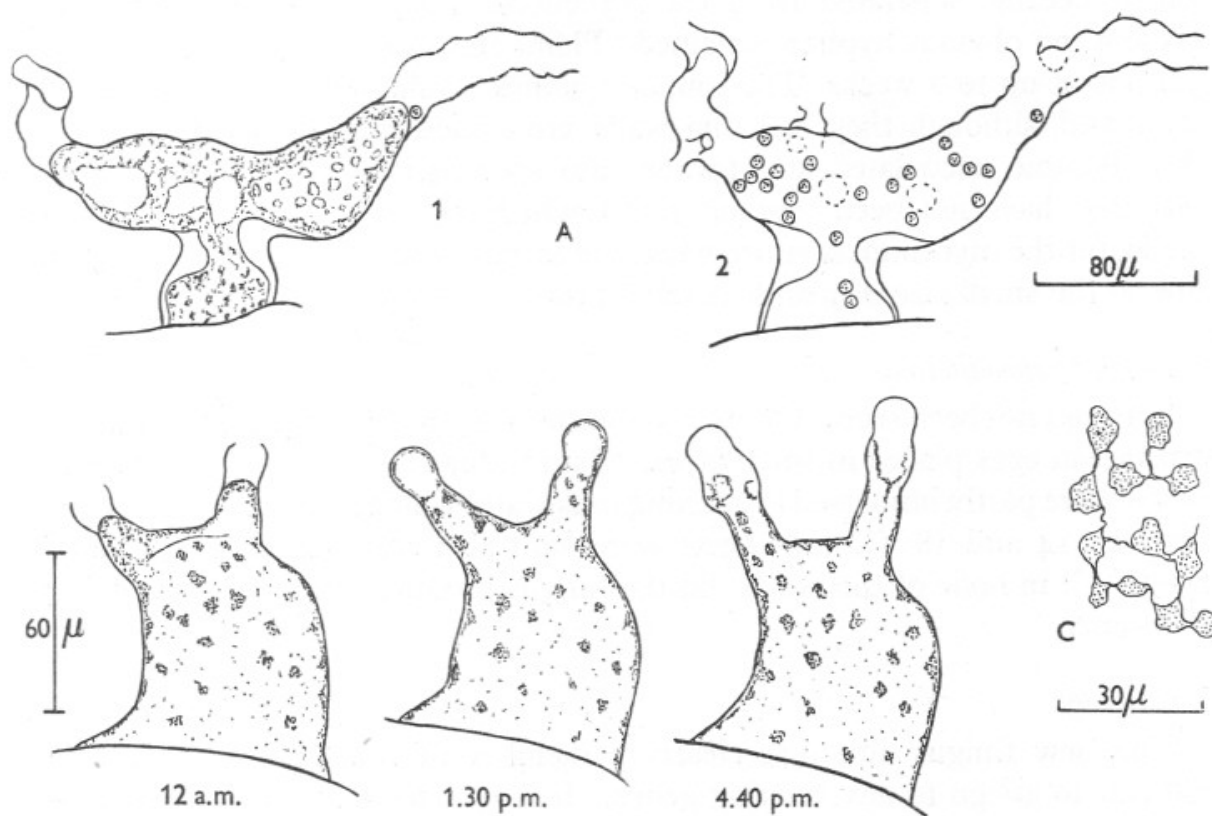

1.30 p.m.
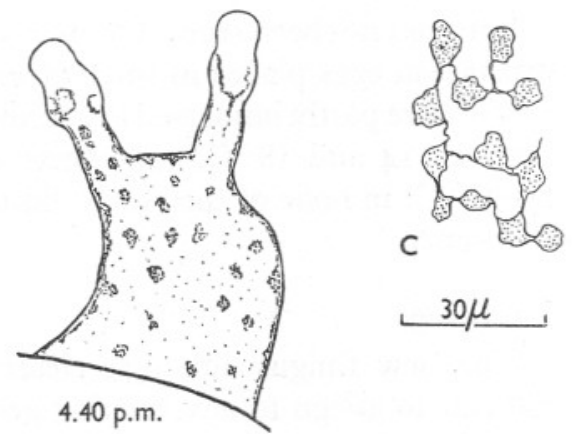

B

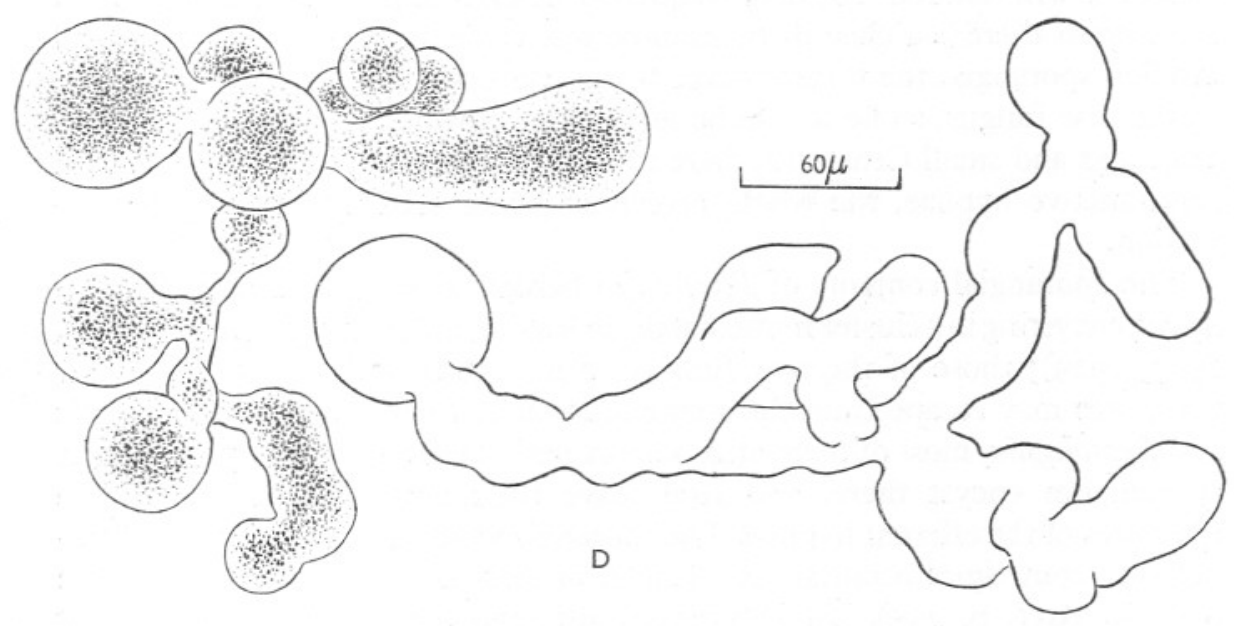

Fig. 5. Plectospira dubia. A and B, two instances of proliferation: in A $\mathrm{I}$ the protoplasm is much vacuolated; in A 2 the apertures of four efferent hyphae on the under surface are indicated by broken lines; C, spore initials in an efferent hypha. D, mycelia producing gemmae, dissected from egg of Gonoplax rhomboides: contents indicated in mycelium on left. 
which became separated from the mycelium. When many gemmae were present, no obvious hyphae remained. Plants remained in this condition for periods of up to 2 weeks. The rounded bodies would appear to be a resting stage and, although they had thin walls, are evidently gemmae. Eventually they became vacuolated and turned into sporangia with efferent hyphae. Gemmae have not been seen on plants which had already produced sporangia, for the mycelium is entirely used up in zoospore formation: this may be due to the small size of plants in small hosts.

\section{Sexual reproduction}

This has not been seen. For over 3 months in 1953 the fungus was grown in crustacean eggs placed in small bowls of sea water of salinity $36-37 \%$; some bowls were partly immersed in running tank water which kept the temperature between 14 and $18^{\circ} \mathrm{C}$, and others were kept at a constant temperature of $\mathrm{I} 5-\mathrm{I} 6^{\circ} \mathrm{C}$ : in none of the bowls did the fungus produce sexual organs during this time.

\section{Taxonomy}

The new fungus although clearly a member of the Saprolegniaceae is difficult to assign to any existing genus. It would seem to resemble Plectospira (Drechsler, 1927, I929) in that the sporangia are composed of inflated elements with efferent hyphae, frequently of uneven diameter, but while in Plectospira there is a clear distinction between slender vegetative hyphae and swollen sporangia, the former never being converted directly into sporangia, in the new fungus, so far as can be seen under crowded conditions in crustacean eggs and small Crustacea, there is no distinction between vegetative and reproductive hyphae, the whole mycelium being used up in zoospore formation.

The sporangial contents of Plectospira behave as in Achlya and Aphanomyces, encysting in a cluster immediately on leaving the sporangium(Drechsler, I927, I929); those of the new fungus do not. Although a few of the first zoospores may escape from the sporangium after the manner of Saprolegnia and Leptolegnia, most of them after a short period of feeble activity within the sporangium encyst there, and later leave their cysts and escape by the apertures of the efferent hyphae. The sporangia would seem to be of the falsenet type sometimes occurring in Achlya, in that the sporangial wall persists (Couch, I93I, p. 225). In Dictyuchus, although the first zoospores encyst within the sporangium, the secondary ones either escape from their cysts directly through the wall of the sporangium, or else in the false-net group the wall of the sporangium quickly disappears.

In both Saprolegnia and Achlya, according to Coker (I923, p. 9), 'it frequently happens that the discharge of the spores is only partial, a few or even a good many spores being left in the sporangium. These retained spores may emerge 
from their cysts, as normally, for a second swimming stage, moving about within the sporangium until they find their way out by its mouth, if they ever do.' This partial retention of the pyriform zoospores in Saprolegnia and Achlya is carried much further in the new fungus and is the normal occurrence; moreover the latter differs from both Saprolegnia and Achlya in that the sporangia have no definite shape, but are lobulate inflated segments.

Rather than create a new genus for this marine fungus, while the sexual organs are unknown, it is proposed to place it provisionally in the genus Plectospira with the specific name dubia.

\section{Diagnosis}

Mycelio plerumque intramatricali, rudi, composito de hyphis irregularibus latitudine $(50-100 \mu)$; sporangiis irregulariter inflatis, subinde proliferosis, depletis per hyphas efferentes, longitudine variabiles et saepe latitudine irregulares; sporangii pariete persistenti; zoosporis primas et secundas capsulas formantibus, primo tamen statu natanti plerumque suppresso; zoosporis plerumque capsulas formantibus intra sporangium postquam paulisper infirmiter nataverunt, postea valide natantibus ad secundum statum; sporis tum 6-8 $\mu$ latitudine cum in capsulas inclusa sunt; gemmis numerosis, sphaeralis, ad Ioo $\mu$ latitudine; partibus sexualibus ignotis.

Mari incolens; parasitica in ovis crustacearum et in parvis crustaceis.

Type material has been deposited in the British Museum (Natural History).

This work was made possible by the kindness of the Board of Studies in Zoology of London University in granting me the use of the London University Table at the Laboratory of the Marine Biological Association at Plymouth, and was done while working on the biology of Pinnotheres. I am indebted to Dr B. Barnes for reading the manuscript. Dr J. Morton has most kindly turned the diagnosis into Latin.

\section{SUMMARY}

A marine fungus, Plectospira dubia n.sp., has been found infecting crustacean eggs and small Crustacea in the Plymouth Laboratory. It has the following characteristics: mycelium mostly intra-matrical, coarse, hyphae 50-100 $\mu$ in diameter. Sporangia irregularly inflated, emptying by efferent hyphae of variable length and frequently of irregular diameter; sometimes proliferous; wall persistent. Zoospores dicystic and dimorphic, but the first swimming stage largely suppressed, the first zoospores mostly encysting within the sporangium after a short period of feeble activity, then swimming in the second stage. The first zoospores pyriform and flagellate (probably biflagellate): in the second motile stage laterally grooved with two laterally inserted flagella. First zoospores about Io $\mu$ long, when encysted $7-8 \mu$ in diameter; in the second motile stage I I-I $2 \mu$ long, when encysted 6-7 $\mu$ in diameter. Gemmae numerous, spherical, up to $100 \mu$ in diameter. Sexual organs so far unknown. 


\section{REFERENCES}

Atkins, D., I929. On a fungus allied to the Saprolegniaceae found in the pea-crab Pinnotheres. F. Mar. biol. Ass. U.K., Vol. I6, pp. 203-I9.

I954 $a$. Further notes on a marine member of the Saprolegniaceae, Leptolegnia marina n.sp., infecting certain invertebrates. F. Mar. biol. Ass. U.K., Vol. 33, pp. $613-25$.

- 1954b. Pythium thalassium n.sp. infecting the egg-mass of the pea-crab Pinnotheres pisum. Trans. Brit. mycol. Soc. vol. 37, pt. 4. (In the Press.)

Coker, W. C., 1923. The Saprolegniaceae, with Notes on other Water Molds. University of North Carolina Press.

Coker, W. C. \& Matthews, V. D., I937. Saprolegniales. N. Amer. Flora, Vol. 2, pt. I.

Couch, J. N., I93I. Observations on some species of water molds connecting Achlya and Dictyuchus. F. Elisha Mitchell sci. Soc., Vol. 46, pp. 225-9.

DreCHSLER, C., I927. Two water molds causing tomato rootlet injury. F. agric. Res., Vol. 34, pp. 287-96.

1929. The beet water mold and several related root parasites. F. agric. Res., Vol. 38, pp. 309-6r. 